\title{
Poço de infiltração para controle de enchentes na fonte: avaliação das condições de operação e manutenção
}

\author{
Infiltration well for local flood control: evaluation of \\ operation and maintenance
}

\section{Ademir Paceli Barbassa \\ Loide Angelini Sobrinha \\ Rodrigo Braga Moruzzi}

\section{Resumo

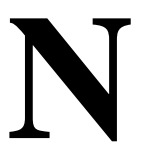

este estudo foram investigados os seguintes aspectos relativos à avaliação de um poço de infiltração construído em escala real: i) tampa/filtro de entrada; ii) permeabilidade do geotêxtil interno ao poço; e iii) tempos de esvaziamento. O poço de infiltração com volume de $3,6 \mathrm{~m}^{3}$ drena área de $241,8 \mathrm{~m}^{2}$. A tampa/filtro foi composta de camadas de areia, brita e geotêxtil dispostos sobre a estrutura metálica. Os anéis de concreto que compõem a estrutura lateral do poço foram revestidos com manta geotêxtil intercalada com blocos cerâmicos. O poço permaneceu em constante operação, entretanto foram simulados eventos específicos para o tempo de esvaziamento. Realizaram-se ensaios da permeabilidade de amostras de geotêxtil, do teor de materiais pulverulentos dos agregados ao poço, ou seja, a brita e a areia que compõem a tampa/filtro. $\mathrm{O}$ geotêxtil apresentou redução média da permeabilidade de $50,7 \%, 7,7 \%$ e $21,2 \%$ nas amostras do fundo, paredes e tampa do poço respectivamente. A areia do filtro da tampa reteve $34,8 \%$ de finos, enquanto a brita reteve $0,13 \%$ de finos no mesmo período. A capacidade hidráulica média do poço foi $34,7 \mathrm{~mm} / \mathrm{h}$. O coeficiente de determinação para os tempos de esvaziamento calculados e medidos foi de 0,97 .

Palavras-chave: Técnicas compensatórias de drenagem. Tempo de esvaziamento. Poço de infiltração.

\section{Abstract}

This study investigated the following aspects regarding a soakaway, i.e. an infiltration well: i) entrance filter device; ii) permeability of the geotextile; and iii) emptying time. The $3.6 \mathrm{~m} 3$ infiltration well drains a roof area of $241.8 \mathrm{~m} 2$. The entrance device is made up of layers of sand, gravel and geotextile set on a metal structure. The concrete rings that form the lateral walls were covered with geotextile, and bricks were laid between the soil and concrete rings. The infiltration well remained in operation during the entire testing period, and specific events were simulated to measure the emptying time. Permeability and fine particle tests were carried out after eight months of operation. Samples of geotextile taken from the bottom, the walls and the entrance device presented average permeability reductions of approximately $50.7 \%, 7.7 \%$ and $21.2 \%$, respectively. The sand in the entrance device retained around $34.8 \%$ of fine particles and the gravel retained $0.13 \%$ in the same period. The infiltration rate was approximately $34.7 \mathrm{~mm} / \mathrm{h}$. The $R 2$ coefficient for measured and calculated times was 0.97.

Recebido em 14/09/14 Aceito em 27/09/13
Keywords: Compensatory technique. Emptying time. Infiltration well. 


\section{Introdução}

Os poços de infiltração são sistemas de retenção de águas pluviais comumente empregados na Europa e nos EUA, juntamente com microrreservatórios de detenção (piscininhas), valas e trincheiras de infiltração. Tais sistemas fazem parte de um rol de alternativas tecnológicas de microescala que têm como função reter água pluvial em detrimento das parcelas escoadas. Especificamente, o poço de infiltração consiste em técnica compensatória denominada pontual (pequena área em planta), a qual visa atenuar os efeitos decorrentes do escoamento superficial direto em sua geração e também pode ser designada como técnica de controle do escoamento superficial direto na fonte. Sua função é infiltrar as águas pluviais, visando amortecer os picos de vazão que possam atingir o sistema de drenagem convencional e, consequentemente, diminuir o volume do escoamento superficial direto pela retenção do volume excedente de chuva no solo.

As técnicas compensatórias de microescala tem ampla faixa de dimensionamento e características técnicas, as quais são dependentes das particularidades locais, tais como regime pluviométrico, característica do solo, profundidade do lençol freático, aspectos legais $\mathrm{e}$ disponibilidade de espaço. No cenário internacional, esses aspectos foram recentemente estudados por Chahar, Graillot e Gaur (2012), Chopra, Stuart e Wanielista (2010), Coughlin, Campbell e Mays (2012), Freni, Mannina e Viviani (2009), Göbel et al. (2009) e GomezUllate et al. (2011); no Brasil esses aspectos particulares e suas condições de contorno podem ser verificados em Angelini Sobrinha (2012), Galavoti (2012), Kawatoko (2012), Lucas (2011), Rojas-Gutierrez (2011), Lima (2009), Silva et al. (2009), Ohnuma Júnior (2008) e Cunha (2004).

O dimensionamento de poço de infiltração pode ser feito por meio do método denominado rain envelope method, conforme recomendado por Urbonas e Stahre (1993) e também apresentado em Blijenberg et al. (1996). Nesse método, o volume de retenção é determinado pela máxima diferença entre a chuva de projeto e a curva de infiltração da água no solo, para cada intervalo de tempo. Os métodos para determinação da capacidade de infiltração da água no solo podem ser encontrados em Paiva e Paiva (2003). A capacidade de infiltração mínima, após saturação do solo, é em geral adotada no projeto de sistemas de infiltração. A comparação entre diferentes modelos para estimativa da infiltração pode ser consultada em Zolfaghari, Mirzaee e Gorji (2012). Assim, o desempenho adequado desse sistema pressupõe a manutenção da taxa de infiltração da água no solo, conforme condições definidas em projeto. Além da retenção da água pluvial escoada em superfície, o poço de infiltração também captura parte do material particulado em suspensão. Esse material particulado fica retido nos filtros do poço e interstícios do solo, o que pode provocar a colmatagem deles, reduzindo a taxa de infiltração e elevando o tempo de esvaziamento previsto para esses sistemas na fase de projeto. O tempo de esvaziamento requerido para sistemas de infiltração deve ser menor que $24 \mathrm{~h}$, de modo que haja volume de espera quando da próxima precipitação (BAPTISTA; NASCIMENTO; BARRAUD, 2005).

Para minimizar o efeito da colmatagem do solo, mantas geotêxteis têm sido instaladas nos sistemas de infiltração. Esses componentes visam reter o material antes da penetração nos interstícios do solo e devem, tanto quanto possível, ser instalados de modo a propiciar sua fácil remoção, visando à limpeza e substituição.

Assim, este trabalho visa investigar a retenção de material suspenso nos componentes do poço de infiltração com função de filtro, quais sejam, tampa/filtro, paredes e fundo, revestidos com manta geotêxtil. A permeabilidade da manta geotêxtil, em suas diferentes posições, foi avaliada antes e após oito meses de operação do sistema. Outro ponto abordado neste trabalho é a análise dos coeficientes de permeabilidade do poço de infiltração, uma vez que estão relacionados aos tempos de esvaziamento. Nesse sentido foram realizados ensaios de campo e analisados trabalhos realizados por Carvalho (2008) e Reis, Oliveira e Sales (2008). Para avaliar o desempenho e auxiliar o projeto do poço de infiltração, o tempo de esvaziamento da unidade em escala real foi modelado por meio do modelo de Puls, apresentado por Cudworth Júnior (1989), em sua versão modificada, que usa como parâmetro de ajuste matemático a permeabilidade calculada. $\mathrm{O}$ artigo inicia-se com a apresentação e avaliação de alguns aspectos construtivos relevantes à execução de poços de infiltração.

\section{Metodologia}

O sistema de infiltração construído em escala real para controle do escoamento superficial direto está localizado no campus da UFSCar, em São Carlos, SP. A cidade localiza-se a $231 \mathrm{~km}$ da capital paulista e possui população total de 221.936 habitantes. A precipitação média anual é de 1.500 mm (PREFEITURA..., 2012). 
O poço de infiltração foi dimensionado empregando o rain envelope method para uma chuva de projeto de 2 anos, utilizando a equação de chuva da cidade de São Carlos elaborada por Barbassa (1991), e recebe como contribuição a drenagem de um telhado de zinco com área de $241,8 \mathrm{~m}^{2}$, provinda de um edifício com menos de 5 anos de construção.

A área em que o experimento foi instalado, bem como a área drenada por ele, situa-se próximo aos laboratórios de Hidrologia, Hidráulica e Mecânica dos Solos do Departamento de Engenharia Civil, local onde foram realizados os ensaios de permeabilidade em campo.

$\mathrm{O}$ poço de infiltração, tal como dimensionado pelo método rain envelope, tem volume aproximado de $3,6 \mathrm{~m}^{3}$ (1,7 $\mathrm{m}$ de profundidade útil), com sistema de condução das águas em canaletas gramadas e a céu aberto. Em sua concepção previram-se tampa metálica com filtros de geotêxtil, areia e brita, anéis de concreto, camadas de tijolo furado interna e externamente aos anéis, emantas geotêxteis internamente ao poço e junto à parede do solo, conforme a Figura 1. Os filtros instalados na tampa e nas paredes interna e externa do poço foram concebidos para reter o material particulado presente no escoamento pluvial. $\mathrm{O}$ anel de concreto possui $1,45 \mathrm{~m}$ de diâmetro externo, 1,35 de diâmetro interno e contém 8 furos na parede lateral, de $50 \mathrm{~mm}$ de diâmetro cada (Figura 2).

Os anéis de concreto foram sobrepostos uns aos outros e assentados em blocos de concreto de dimensões (19x14x30) cm para dar estabilidade ao anel, já que o solo não foi compactado, para não reduzir a capacidade de infiltração no solo.

Os blocos cerâmicos têm papel estrutural e hidráulico, na medida em que visam conter o solo e contribuir para a distribuição da água do poço ao solo. O componente de alvenaria utilizado foi o bloco cerâmico com dimensões de (19x9x19) cm e com 8 furos de $3,3 \mathrm{~cm}$ de diâmetro. O esquema de disposição dos blocos é apresentado na Figura 3. A manta geotêxtil foi colocada no interior do poço (paredes internas), no fundo do poço, na interface solo-bloco (parede externa) e sobre a tampa de metal, conforme a Figura 4.

A manta geotêxtil foi costurada com transpasse de $50 \mathrm{~cm}$. Há recomendações para que a manta geotêxtil tenha um transpasse de no mínimo de 15 cm na construção de técnicas de infiltração (MARYLAND..., 2000). As características hidráulicas da manta geotêxtil selecionada são apresentadas na Tabela 1. O uso dos blocos externamente aos anéis poderia ser substituído por brita, dependendo do processo construtivo.

Figura 1 - Detalhes construtivos do poço de infiltração - corte esquemático

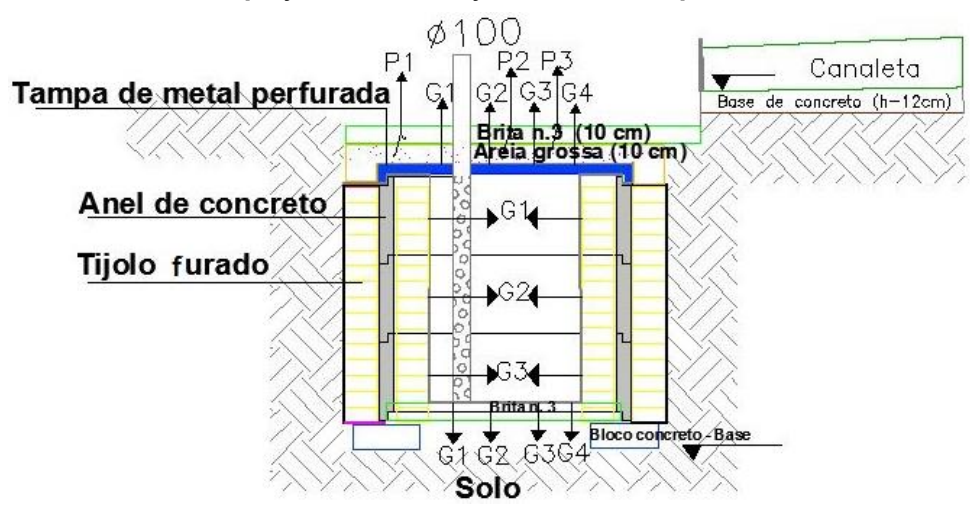

Nota: P1, P2 e P3 - Amostras de brita e areia da tampa do filtro. G1 a G4 - Amostras de manta geotêxtil do filtro da tampa, paredes e fundo do poço. Foram realizadas duas sondagens de percussão, indicando N.A. de 9,8 m em ambas.

Figura 2 - Anel de concreto com 8 furos de 50 mm, 1,45 m de diâmetro externo e 1,35 m de diâmetro
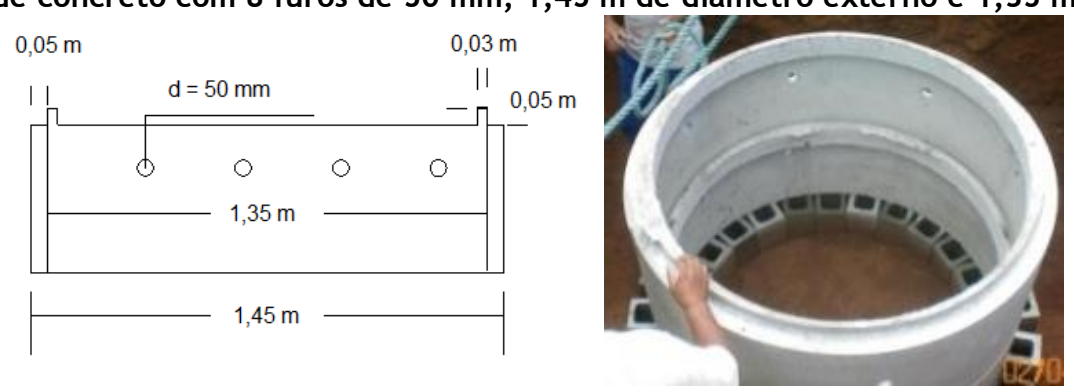

Nota: espaçamento radial entre furos de $0,53 \mathrm{~m}$ - em corte e foto. 


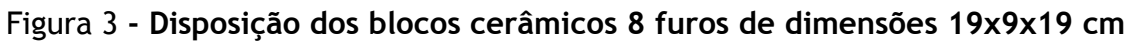
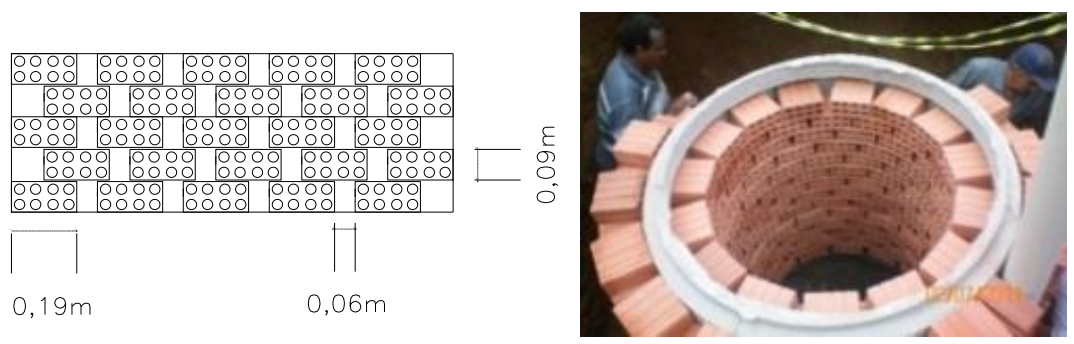

Figura 4- Manta geotêxtil colocada nas paredes internas e externas do poço de infiltração

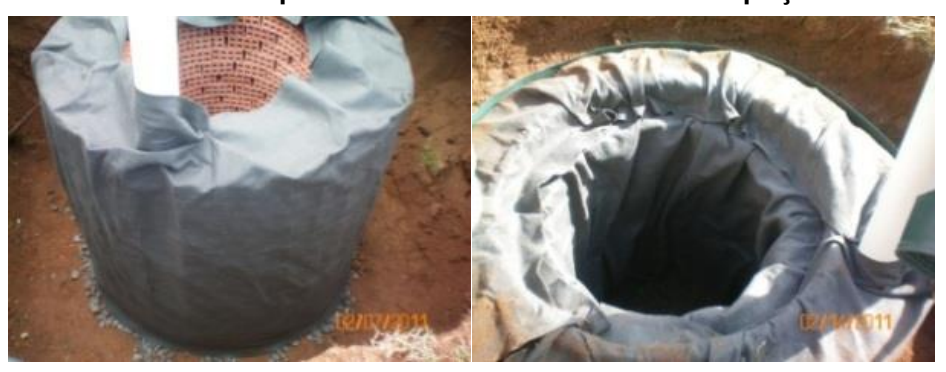

Tabela 1- Propriedades hidráulicas da manta geotêxtil GF21/400

\begin{tabular}{c|c|c}
\hline Propriedades & Norma de Ensaio & GEOFORT/400 \\
\hline Permissividade & ASTM - D 4491 (AMERICAN..., 1999) & $1,02 \mathrm{~s}^{-1}$ \\
Permeabilidade normal & ASTM - D 4491 (AMERICAN..., 1999) & $4 \times 10^{-3} \mathrm{~m} / \mathrm{s}$ \\
Transmissividade & ASTM - D 4716 (AMERICAN..., 2008) & $1,05 \times 10^{-5} \mathrm{~m}^{2} / \mathrm{s}$ \\
Abertura de filtração & AFNOR - G 38017 (ASSOCIATION..., 1999) & $80 \mu \mathrm{m}$ \\
\hline
\end{tabular}

Fonte: Geofort (2014)..

A tampa tem a função de fechamento e de base para a manta geotêxtil bem como para as camadas de areia e brita, dispostas sobre a mesma. Portanto, a tampa foi construída com barra cantoneira de aço tratada com tinta anticorrosiva, com dimensões $1 / 8$ " x $1 / 2$ " e $6 \mathrm{~mm}$ de espessura, formando uma malha de $30 \mathrm{~cm} \times 30 \mathrm{~cm}$. Sobre a grade de aço foram soldadas barras de aço de $5 \mathrm{~mm}$ de espessura, formando uma malha de $5 \mathrm{~cm}$ x $5 \mathrm{~cm}$. O elemento estrutural da tampa/filtro é apresentado na Figura 5. Na Figura 6 é apresentado o poço construído, com detalhe dos poços de monitoramento.

O tubo de PVC colocado no interior do sistema de infiltração possui furos distribuídos de $1,5 \mathrm{~cm}$ e foi utilizado para coleta de dados de nível e coleta de água para os ensaios de qualidade.

Inicialmente, foi colocada uma camada de $10 \mathrm{~cm}$ de areia grossa lavada sobre a tampa do poço (sobre a manta geotêxtil). A areia e a manta geotêxtil desempenham a função de filtro na retenção de finos, visando auxiliar no retardamento do processo de colmatagem do poço. A areia da tampa foi colocada no início da construção do poço, conforme ilustrado na Figura 7. Colocou-se uma camada de $20 \mathrm{~cm}$ de brita $\mathrm{n}^{\circ} 3$ no fundo e de
$10 \mathrm{~cm}$ sobre a tampa do poço. A brita foi lavada antes de sua instalação, conforme a Figura 8.

$\mathrm{O}$ esquema de funcionamento do poço de infiltração é constituído das etapas subsequentes, as quais podem ser mais bem compreendidas se avaliadas conjuntamente com a Figura 9:

(a) coleta da água pluvial do telhado do prédio até as canaletas gramadas;

(b) condução da água pluvial pelas canaletas gramadas até o vertedor triangular;

(c) medição das vazões de entrada;

(d) passagem pelo meio filtrante da tampa composta de areia, geotêxtil e brita;

(e) passagem pelo geotêxtil interno ao poço em toda a área das paredes e pelo fundo;

(f) passagem pelos furos dos anéis de concreto e distribuição pelas camadas de tijolos internos e externos;

(g) passagem pelo geotêxtil externo; e

(h) infiltração no solo das paredes e do fundo do poço. 
Para acondução da água pluvial, parte da instalação predial foi desconectada e foram construídas canaletas gramadas, utilizadas para escoar as águas provenientes do prédio até a entrada o poço de infiltração. As canaletas seguiram o princípio de desenvolvimento de baixo impacto (LID), conforme apresentado em Tavanti e Barbassa (2012), na medida em queforamintegradasa paisagem local, desempenhando o papel de condução da água pluvialpor dispositivo permeável e com cobertura vegetal, auxiliando na redução de velocidade do escoamentoe na retenção de sólidos.

Sondagens de percussão no local do sistema filtrovala-trincheira (FVT) indicaram nível do lençol freático a $9,8 \mathrm{~m}$.

Figura 5- Estrutura metálica da tampa/filtro - medidas em metro, menos quando indicado
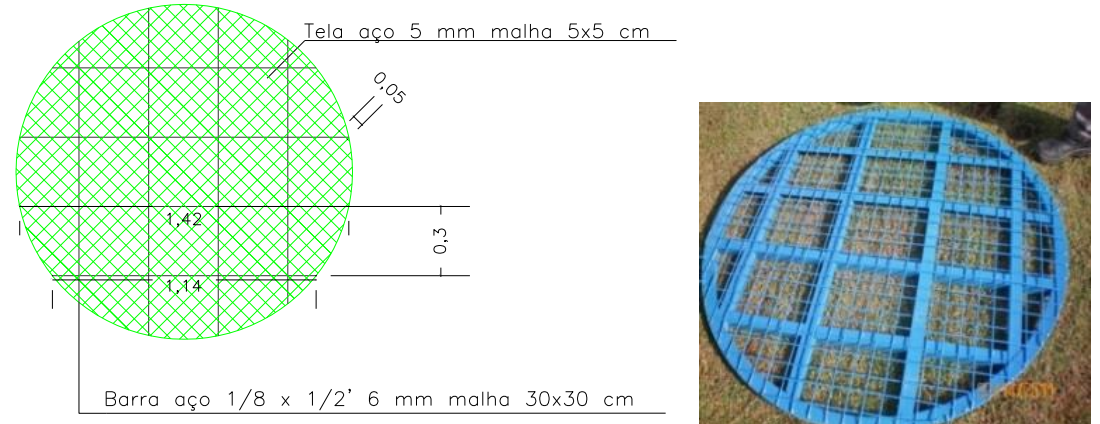

Figura 6- Tubo de $150 \mathrm{~mm}$ de PVC para coleta de dados (poço de monitoramento)

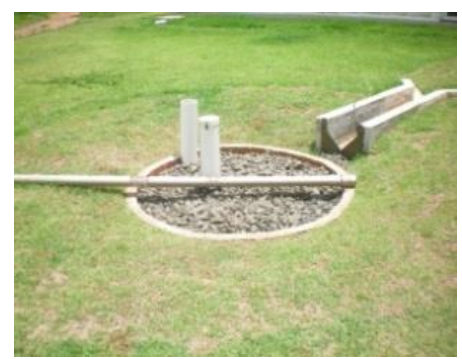

Figura 7 - Camada de $10 \mathrm{~cm}$ de areia colocada em cima da tampa de metal sobre a manta geotêxtil na construção do poço de infiltração

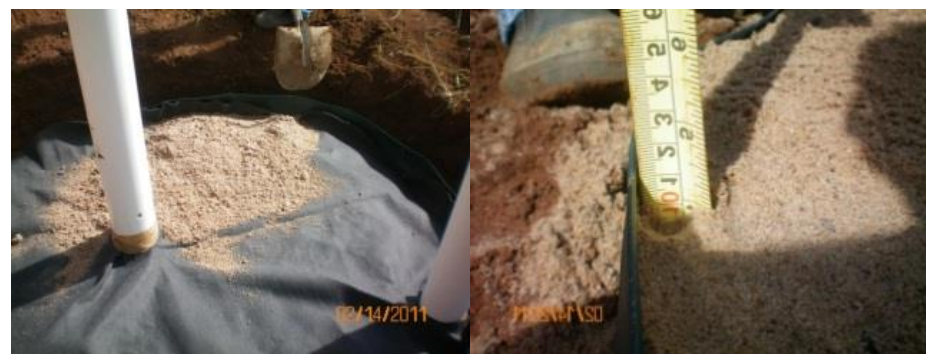


Figura 8- Lavagem da brita para utilização dela no fundo e na tampa do poço

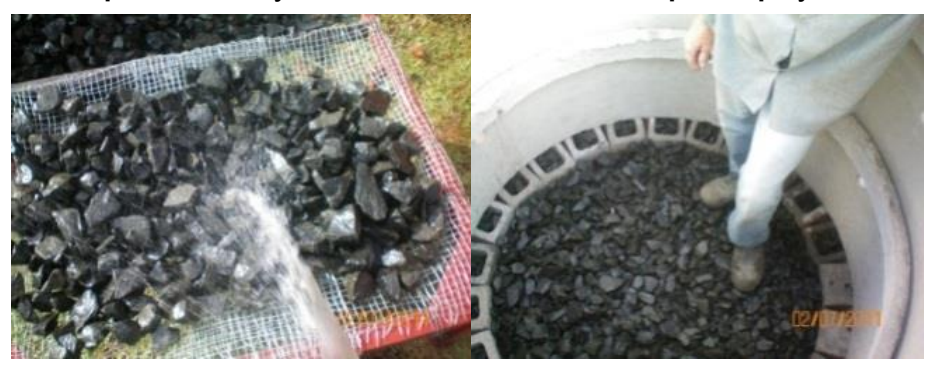

Figura 9 - Esquema de alimentação do poço de infiltração: caminho da água pluvial do telhado do prédio ao poço de infiltração por meio das canaletas gramadas

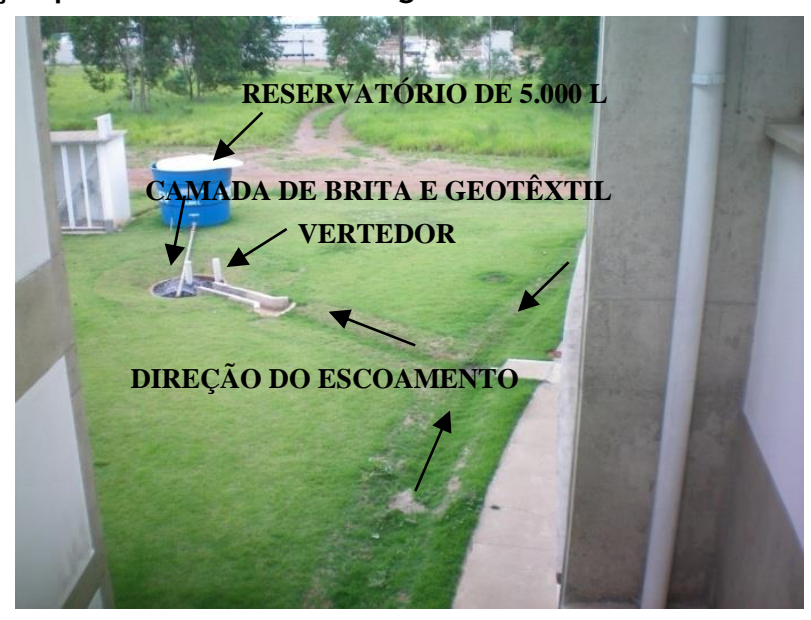

Figura 10 - Hidrograma de entrada típico e variação do nível de água (NA),medidos no poço de infiltração

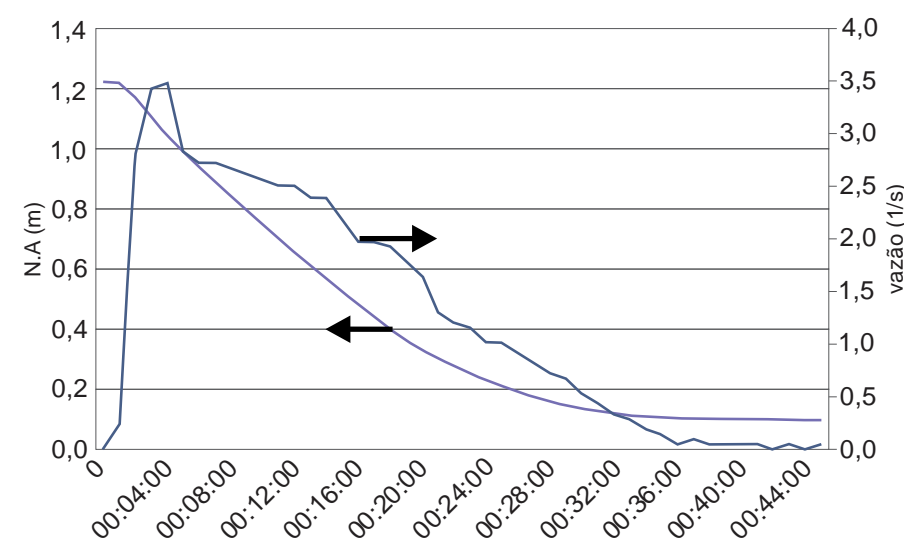

Figura 11 - Medidor de nível instalado no interior do poço de monitoramento, constituído por tubo de PVC utilizado para coleta de dados de nível de água no interior do poço

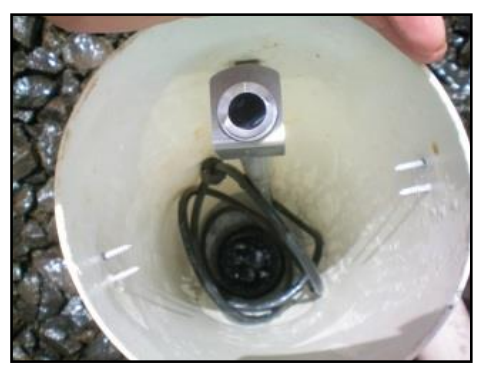

96 Barbassa, A. P.; Angelini Sobrinha, L.; Moruzzi, R. B. 
Após o enchimento do reservatório, foram adicionados sólidosprovenientes do solo nas porções de silte e argila, coletadosna localidade do poço, de modo a simular os sólidos suspensos transportados pelo escoamento superficial direto. A quantidade de solo adicionado na água do reservatório foi baseadaem resultados obtidos por Rojas-Gutierrez (2011), que quantificou sólidos suspensos das águas pluviais precipitadas (atmosfera) e provenientes dos telhados para a mesma localidade. Antes de realizar a descarga da água do reservatório no poço, a suspensãode concentração de $10 \mathrm{mg} / \mathrm{L}$ foi misturada por 10 $\min$.

\section{Ensaios de laboratório realizados para análise do processo de colmatagem do poço de infiltração}

Apresentam-se no Quadro 1 as datas, os tipos, os locais e o número de amostras, além dos procedimentos normativos observados para a realização dos ensaios, visando avaliar a presença de material pulverulento retido nas parcelas de brita, areia e manta geotêxtil instalados no poço de infiltração, bem como a permeabilidade da manta geotêxtil.

Os ensaios nas amostras do filtro da tampa do poço antes da instalação foram realizados em laboratório. As amostras foram denominadas "limpas" quando compostas de amostras de geotêxtil novo, de areia e de brita lavada (antes do uso). Foram denominadas "sujas" quando retiradas do poço após 4 e 8 meses de funcionamento dele.

Nos ensaios para adeterminação da permeabilidade do meio filtrante, colocou-se em cada tubo de ensaio com diâmetros de $14,41 \mathrm{~cm}$ e $13,57 \mathrm{~cm}$ (cada tubo foi medido com paquímetro separadamente e calcularam-se suas respectivas áreas) uma amostra de manta geotêxtil, $10 \mathrm{~cm}$ de areia e $10 \mathrm{~cm}$ de brita, submetida a uma carga de água constante de $20 \mathrm{~cm}$ (lâmina de água máxima sobre a tampa do poço sem que houvesse extravasamento). $\mathrm{O}$ fornecimento de água para o filtro foi contínuo, assim se coletava em uma proveta graduada a água que passava pelo filtro em intervalos de $60 \mathrm{~s}$.

As coletas no filtro limpo foram realizadas três vezes consecutivas para cada intervalo de tempo de 15 min, tendo duração total de 2 h. Já as coletas de água do filtro sujo também eram realizadas três vezes consecutivas, porém em intervalos de tempo maiores, tendo duração total de $24 \mathrm{~h}$ de ensaio.

A permeabilidade foi determinada por meio do volume coletado em 60 smultiplicado pela altura do corpo de prova de $20 \mathrm{~cm}(10 \mathrm{~cm}$ de areia e 10 $\mathrm{cm}$ de brita). Esses valores foram divididos pela área dos tubos de ensaio, pela altura da carga disponível constante de $20 \mathrm{~cm}$ e pelo tempo. A Equação 1, apresentada por Stancati, Nogueira e Vilar (1981), foi empregada para a determinação da capacidade de infiltraçãoensaiada.

$K=\frac{V H}{A L t}$

Eq. 1

Onde:

$\mathrm{K}=$ permeabilidade do filtro $(\mathrm{cm} / \mathrm{s})$;

$\mathrm{V}=$ volume coletado de amostra $\left(\mathrm{cm}^{3}\right)$;

$\mathrm{H}=$ altura do corpo de prova $(\mathrm{cm})$;

$\mathrm{An}=$ área do tubo de ensaio $\left(\mathrm{cm}^{2}\right)$;

$\mathrm{L}=$ altura de carga disponível $(\mathrm{cm})$; e

$\mathrm{t}=$ tempo $(\mathrm{s})$

Quadro 1 - Ensaios para análise da colmatagem do poço por meio de medidas de material pulverulento retido e por meio de ensaios de permeabilidade

\begin{tabular}{|c|c|c|c|c|}
\hline Data & Tipo de ensaio & $\begin{array}{l}\text { Local do } \\
\text { filtro }\end{array}$ & $\begin{array}{c}\text { Número de } \\
\text { amostras/ensaios }\end{array}$ & Normas/Referência \\
\hline $\begin{array}{c}\text { Antes da } \\
\text { construção do } \\
\text { poço }\end{array}$ & $\begin{array}{c}\text { Teor de material } \\
\text { pulverulento da areia e brita }\end{array}$ & $\begin{array}{l}\text { Amostras da } \\
\text { tampa }\end{array}$ & $\begin{array}{l}1 \text { areia } \\
1 \text { brita }\end{array}$ & $\begin{array}{c}\text { NBR } 7219 \\
\text { (ASSOCIAÇÃO..., 1987) }\end{array}$ \\
\hline $\begin{array}{c}4 \text { meses de } \\
\text { funcionamento } \\
\text { do poco }\end{array}$ & $\begin{array}{c}\text { Teor de material } \\
\text { pulverulento da areia e brita }\end{array}$ & $\begin{array}{l}\text { Amostras da } \\
\text { tampa }\end{array}$ & $\begin{array}{l}1 \text { areia } \\
1 \text { brita }\end{array}$ & $\begin{array}{c}\text { NBR } 7219 \\
\text { (ASSOCIAÇÃO...,, 1987) }\end{array}$ \\
\hline \multirow{3}{*}{$\begin{array}{c}8 \text { meses de } \\
\text { funcionamento } \\
\text { do poço }\end{array}$} & $\begin{array}{c}\text { Teor de material } \\
\text { pulverulento da areia e brita }\end{array}$ & $\begin{array}{c}\text { Amostras da } \\
\text { tampa }\end{array}$ & $\begin{array}{l}1 \text { areia } \\
1 \text { brita }\end{array}$ & $\begin{array}{c}\text { NBR } 7219 \\
\text { (ASSOCIAÇÃO...,, 1987) }\end{array}$ \\
\hline & Permeabilidade do geotêxtil & $\begin{array}{c}\text { Paredes } \\
\text { internas, } \\
\text { fundo e tampa }\end{array}$ & 56 corpos de prova & $\begin{array}{c}\text { D } 4491 \\
(\text { AMERICAN..., 1999) }\end{array}$ \\
\hline & $\begin{array}{l}\text { Permeabilidade do filtro da } \\
\text { tampa, composto de areia, } \\
\text { brita e geotêxtil }\end{array}$ & $\begin{array}{l}\text { Amostras da } \\
\text { tampa }\end{array}$ & $\begin{array}{l}3 \text { filtros limpos } \\
3 \text { ensaios filtro } \\
\text { sujo }\end{array}$ & $\begin{array}{c}\text { NBR } 13292 \\
\text { (ASSOCIAÇÃO...,, 1995) }\end{array}$ \\
\hline
\end{tabular}




\section{Condutividade hidráulica do poço de infiltração}

O tempo de infiltração foi inicialmente determinado por meio do valor calculado, conforme resultados obtidos em campo (Equação 1). Posteriormente, utilizaram-se ferramentas de ajuste entre os níveis de água medidos pelo sensor de nível e os calculados indiretamente pelo método de Puls, empregado por ser simples em sua concepção e capaz de representar as etapas de funcionamento do sistema e calcular tanto as vazões de saída, que não foram monitoradas, como os níveis de água. O método possibilitou a incorporação e calibração de parâmetros de entrada obtidos em campo. Assim, a partir da atribuição do valor inicialmente calculado $(\mathrm{k})$, determinou-se o valor de $\mathrm{k}$ otimizado, denominado de ko, obtido por meio de regressão não linear entre os níveis de água medidos e calculados, executada com a ferramenta Solver. A restriçãoimposta ao parâmetro de ajuste ko foi definida conforme as faixas de condutividade hidráulica comumente encontradas para o tipo de solo estudado. No decorrer de cada evento simulado, o valor de ko foi considerado constante. $\mathrm{O}$ ajuste foi avaliado graficamente justapondo-se os níveis de água medidos e calculados, pela reta de ajuste perfeito (razão 1:1) e também pelo coeficiente de determinação $\left(\mathrm{R}^{2}\right)$. A função objetivo empregada foi a diferença dos quadrados entre dados medidos e calculados, a qual foi minimizada durante o processo de ajuste. $\mathrm{O}$ erro em módulo foi determinado pela razão entre a diferença dos valores medidos e a dos calculados pelo valor medido.

Assim, o valor obtido de ko representa o melhor ajuste entre os valores medidos e calculados do nível de água no poço de infiltração em função do tempo, para cada ensaio realizado. Dessa forma, o valor de ko representa a infiltração tal como ocorreu em escala real, incorporando em seu valor numérico todos os efeitos fenomenológicos decorrentes da infiltração no solo em sua condição multifatorial.

A modelagem permitiu a avaliação do tempo de esvaziamento para as diferentes situações investigadas.

\section{Tempos de esvaziamentodo poço de infiltração}

O tempo de esvaziamento observadopara cada evento simulado foi determinado a partir da variação da lâmina máxima de água no poço $\left(\mathrm{NA}_{\max }\right.$ ) até a lâmina de $20 \mathrm{cmem}$ relação ao fundo do poço (valor em que a carga hidráulica é pequena). Os tempos de esvaziamento para cada evento foram calculados pela Equação 2. A vazão de saída empregada para a determinação do ko foi calculada a partir do conjunto de operações apresentados na Equação 3. A razão pelo uso da carga hidráulica de $20 \mathrm{~cm}$ apresenta-se no item resultados.

$\mathrm{Dv}=\frac{\mathrm{V} \text { max }}{\mathrm{Q}_{\mathrm{s}}(t)}$

Onde:

$\mathrm{D}_{\mathrm{v}}=$ tempo de esvaziamento (s);

$\mathrm{V}_{\max }=$ volume máximo de água armazenado no poço, obtido pelo método de Puls $\left(\mathrm{m}^{3}\right)$; e

$\mathrm{Q}_{\mathrm{S}}(\mathrm{t})=$ vazão de saída média obtida pelo método de Puls $\left(\mathrm{m}^{3} / \mathrm{s}\right)$ em intervalos discretizados de tempo $(\mathrm{t})$.

A variação do volume armazenado para cada intervalo de tempo é obtida integrando-se a equação de continuidade no tempo t, resultando na Equação 3 (BAPTISTA; NASCIMENTO; BARRAUD, 2005)

$\int_{V_{t}}^{V_{(t+1)}} d V=\int_{t \Delta t}^{(t+1) \Delta t} I(t) d t-\int_{t \Delta t}^{(t+1) \Delta t} Q(t) d t \quad E q .3$

Reescrevendo na forma de diferenças finitas, obtém-se (Equação 4):

$\frac{2 V_{t+1}}{\Delta t}+Q_{t+1}=I_{t}+I_{t+1}-Q_{t}+\frac{2 V_{t}}{\Delta t}$

As incógnitas, portanto, são os volumes e vazões em $t+1 ; V_{t+1}$ e $Q_{t+1}$, que podem ser obtidas resolvendo-se iterativamente as equações 4 a 7 e a relação entre Qversus $2 V / d t+Q s$, construída a partir da relação entre o N.A. no poço e o volume e a descarga no solo (CUDWORTH JÚNIOR, 1989).

As vazões de saída foram separadas nas parcelas de fundo e parede, pois o nível varia com o tempo $(\mathrm{h}(\mathrm{t}))$.

$\mathrm{Q}_{\mathrm{f}}(\mathrm{t})=\mathrm{k}$. Af

Eq. 5

$\mathrm{Q}_{\mathrm{p}}(\mathrm{h}(\mathrm{t}))=\mathrm{k} \cdot \mathrm{h}(\mathrm{t}) \cdot \pi \mathrm{D}$

Eq. 6

$\mathrm{Q}_{\mathrm{S}}(t)=\sum_{\mathrm{t}=0}^{\mathrm{T}} \mathrm{Q}_{\mathrm{f}}(\mathrm{t})+\mathrm{Q}_{\mathrm{p}}(\mathrm{t})$

Eq. 7

Onde:

$Q_{f}=$ a vazão de infiltração pelo fundo do poço $\left(\mathrm{m}^{3} / \mathrm{s}\right)$;

$k=$ a condutividade hidráulica à saturação, usado como parâmetro de ajuste do modelo aos resultados experimentais $(\mathrm{m} / \mathrm{s})$;

$A f=$ a área de fundo do poço $\left(\mathrm{m}^{2}\right)$;

$D=$ o diâmetro do poço $(\mathrm{m})$; 
$Q_{p}(\mathrm{~h}(\mathrm{t}))=$ a vazão de infiltração pelas paredes do poço $\left(\mathrm{m}^{3} / \mathrm{s}\right)$, a qual depende do nível de água $(h)$ em cada intervalo discretizado de tempo $(\mathrm{t})$; e

$h(t)=$ o nível de água no poço $(\mathrm{m})$ para cada intervalo de tempo $t$ discretizado em intervalos de tempo de $1 \mathrm{~min}$.

Observações: para $t \rightarrow \infty, h(t) \rightarrow$ zero. O valor de $h_{\text {max }}$ representa o maior valor medido de $h(t)$ em cada experimento. Quando $k$ resulta da minimização da função objetivo, lê-se $k=k o$. $Q_{s}$ é a vazão de saída para o solo e corresponde à somatória da vazão de fundo e da parede para cada intervalo de tempo.

Dessa forma, a Equação 2, correspondente ao tempo de esvaziamento $(D v)$, pode ser reescrita conforme a Equação 8.

$$
D v=\frac{h_{\max } \cdot A f}{\overline{Q_{\text {saida }}}}
$$

Onde $h_{\max }$ corresponde à razão entre o $V_{\max }$ e a $A f$.

Para cada evento, simulado pelo descarregamento do reservatório, foi determinado o período de retorno correspondente $(T r)$, determinado conforme a Equação 9, desenvolvida por Barbassa (1991), considerando a duração total do evento simulado.

$i=\frac{28,03 . T r^{0,199}}{(t+16)^{0,936}}$

Onde:

$i=\mathrm{a}$ intensidade $\mathrm{em} \mathrm{mm} / \mathrm{h}$; $\mathrm{e}$

$\operatorname{Tr}=$ o período de retorno em anos.

Ressalta-se que a Equação 9 também foi empregada para dimensionamento do poço de infiltração, o qual foi determinado a partir do rain envelope method, adotando-se $T r$ de 2 anos.Salienta-se que a duração da chuva é aquela que produz o maior volume do poço. A escolha do $\operatorname{Tr}$ de 2 anos decorreu da necessidade de avaliar a operação do poço de infiltração em condiçõeslimite, o que seria dificultado caso o valor de $T r$ fosse mais elevado (p.ex. 10 anos).

\section{Resultados e discussão}

\section{Sobre o teor de material pulverulento na areia e na brita do filtro datampa/filtro}

$\mathrm{O}$ poço permaneceu em operação durante toda a fase de investigação, entretanto foram simulados eventos específicos para obtenção e modelagem do tempo de esvaziamento. As medições indicaram que a areia apresentou um aumento de $56 \%$ de material pulverulento depois de 4 meses de funcionamento do poço. A brita não apresentou variação do teor do material nesse período. Verificou-se nas amostras retiradas 8 meses após a construção do poço aumento de material pulverulento de $35 \%$ na areia e de $0,13 \%$ na brita em relação às amostras novas. Houve, portanto, redução do material pulverulento entre 4 e 8 meses de funcionamento.

Uma das possíveis explicações para o maior teor de material pulverulento na areia das amostras retiradas 4 meses após a construção do poço foi a não estabilização do solo no entorno do poço. Isso pode ter ocasionado transporte de solo para a tampa/filtro do poço, acelerando sua colmatagem. Identificado o problema, foi colocado um limitador de grama no entorno do poço até que o solo apresentasse estabilização adequada.

No entanto, vale mencionar que os efeitos decorrentes do transporte de solo e seu possível transpassepelo componente tampa/filtroforam indiretamentecontabilizados por meio da avaliação dos tempos de esvaziamento medido e calculado para cada evento e constituem situação real da operação do sistema.

Assim, ao se compararem as amostras retiradas aos 8 meses de funcionamento com as amostras retiradas aos quatro meses de funcionamento do poço, percebe-se que o percentual de material pulverulento das amostras de areia diminuiu de $56 \%$ para $35 \%$. Esse fato pode ser atribuído à lavagem do meio filtrante com a ocorrência sucessiva de chuvas, que nesse período totalizou $179 \mathrm{~mm}$. Tal fato evidencia a necessidade da instalação de manta geotêxtil, mesmo quando são utilizadas areia e brita, as quais são responsáveis por reter materiais com maiores granulometrias.

Em decorrência da instabilidade do solo quando da construção dossistemas de infiltração, Schueler (1987) recomenda evitar o escoamento superficial direto para as técnicas compensatóriasem construção, ou seja,até que a vegetação cubra e estabilize o solo no entorno, evitando o arraste de sedimentos para dentro do poço de infiltração.

Em investigação recente em área circunvizinha, Lucas (2011) encontrou uma média de redução de finos em um sistema filtro-vala-trincheira de infiltração de $29 \%$ na brita e de $58 \%$ na areia, em ensaios realizados um ano após a construção do sistema. Ressalta-se que os ensaios de Lucas (2011) foram realizados dentro dos limites da mesma bacia hidrográfica e com as mesmas características físicas do solo. A presença de finos deveu-se também à ausência de procedimento apropriado para estabilização do solo no entorno. 


\section{Sobre a importância das camadas de areia e de brita da tampa/filtro}

Conduziram-se dois tipos ensaios de laboratórios, em triplicada, simulando o filtro sobre a tampacom função de filtro (tampa/filtro): um com areia e brita lavada, e outro com areia e brita com 8 meses de uso, e geotêxtil novo em ambos.Os ensaios foram conduzidos com amostras coletadas do poço de infiltração.

Os ensaios das amostras de filtro limpo tiveram duração de $2 \mathrm{~h}$, pois se percebeu que a permeabilidade, ou seja, a velocidade com que a água passava pelo filtro (volume dividido pelo tempo) mantinha-se constante. Já os ensaios realizados nos filtros sujos tiveram duração de 24 $\mathrm{h}$, tempo suficiente para que a permeabilidade se tornasse constante. As bancadas dos ensaios realizados são apresentadas na Figura 12.

A média da taxa inicial de infiltração do filtro limpo foi de $3.353,4 \mathrm{~mm} / \mathrm{h}$, e a média da taxa final foi de $3.364,9 \mathrm{~mm} / \mathrm{h}$, apresentando um aumento médio da permeabilidade de $0,61 \%$. A taxa no filtro sujo com 8 meses de uso apresentou uma média da taxa inicial de $1.723,0 \mathrm{~mm} / \mathrm{h}$, e média da taxa final, de $1.404,2 \mathrm{~mm} / \mathrm{h}$, o que representa uma média da redução da permeabilidade nos três ensaios de 19,4\%, sendo a maior perda da permeabilidade no ensaio 1 do filtro sujo $(34,6 \%)$.

A variação da permeabilidade em relação aos filtros nas condições denominadas limpo e sujo foi de 58,3\%. Essa redução mostra um papel importante das camadas de areia e brita no filtro. Isso provavelmente ocorreu devido à construção do poço em época de chuvas, sem que houvesse adequada estabilização do solo no entorno, o que pode ter sobrecarregado a tampa/filtro com material transportado. Evidentemente, a ausência desse componente (tampa/filtro) implicaria maior prejuízo àcapacidade de infiltração do poço. Assim, como fruto dessa experiência construtiva, recomenda-se que o poço seja construído em época de seca e que o solo da área drenada seja contido adequadamente.

No entanto, esses ensaios permitiram avaliar o desempenho do componentetampa/filtro bem como da manta geotêxtil. Verificou-se que a vazão de entrada com ocomponentetampa/filtro sujo foi de apenas $0,68 \mathrm{l} / \mathrm{s}$, para uma área da tampa/filtro de $1,76 \mathrm{~m}^{2}$ e permeabilidade de $1.404,2 \mathrm{~mm} / \mathrm{h}$. Vale mencionar que, embora a areia tenha um papel importante na retenção de sólidos, ela limitou a vazão de entrada, uma vez que introduziu uma perda de carga adicional ao sistema, razão pela qual a camada de areia foi retirada após 8 meses de uso.

\section{Sobre a variação da permeabilidade do geotêxtil devido à colmatagem}

O solo do local em que foi instalado o sistema de infiltração, objeto do presente estudo, foi classificado como Areia Média Argilosa - SC, segundo a Classificação Unificada, citada por Souza Pinto (2000) e pelo método Soil Conservation Service (SCS), conforme composição granulométrica apresentada na Tabela 2 .

Os resultados dos ensaios realizados nas amostras de geotêxtil novo e nas amostras retiradas após 8 meses de funcionamento do poço sãoapresentados Tabela 3. Pode-se observar na Tabela 4 maior redução da permeabilidade nas amostras do fundo (41\% a 68\%), com média de 50,7\%, indicando forte redução da permeabilidade. As amostras das paredes foram menos afetadas, com redução máxima de permeabilidade de $19 \%$ (nas proximidades do fundo) e redução média de 7,6\%. Nas amostras da tampa/filtro a redução da permeabilidade máxima foi de $26 \%$, e média de $21,3 \%$.

As amostras de geotêxtil novo apresentaram permeabilidade de $19.672,2 \mathrm{~mm} / \mathrm{h}\left(5,46 \times 10^{-3}\right.$ $\mathrm{m} / \mathrm{s}$ ), sendo esta superior à permeabilidade apresentada no catálogo do fabricante do produto, que é de $14.400 \mathrm{~mm} / \mathrm{h}\left(4,0 \times 10^{-3} \mathrm{~m} / \mathrm{s}\right)$.

Merece destaque o fato de que, mesmo para as condições em que o geotêxtil apresentou maiores reduções da permeabilidade, correspondente ao fundo o valor médio de $9.712 \mathrm{~mm} / \mathrm{h}\left(2,7 \times 10^{-3}\right.$ $\mathrm{m} / \mathrm{s}$ ), este é muito superior à permeabilidade do solo (da ordem de $5,5 \times 10^{-6} \mathrm{~m} / \mathrm{s}$ ), não sendo, assim, o geotêxtil limitante à infiltração de água.

Da mesma forma, a redução da permeabilidade do geotêxtil da tampa de $11 \%$ a $26 \%$ mostrou-se relativamente baixa. Isso é positivo, pois não foi reduzida a vazão de entrada significativamente, viabilizando a proposta da tampa/filtro, a qual foi também concebida visando à fácil remoção para limpeza e manutenção. 
Figura 12 - Aparato experimental para realização dos ensaios de permeabilidade dos meios filtrantes compostos por geotêxtil, areia e brita para diferentes tempos de funcionamento

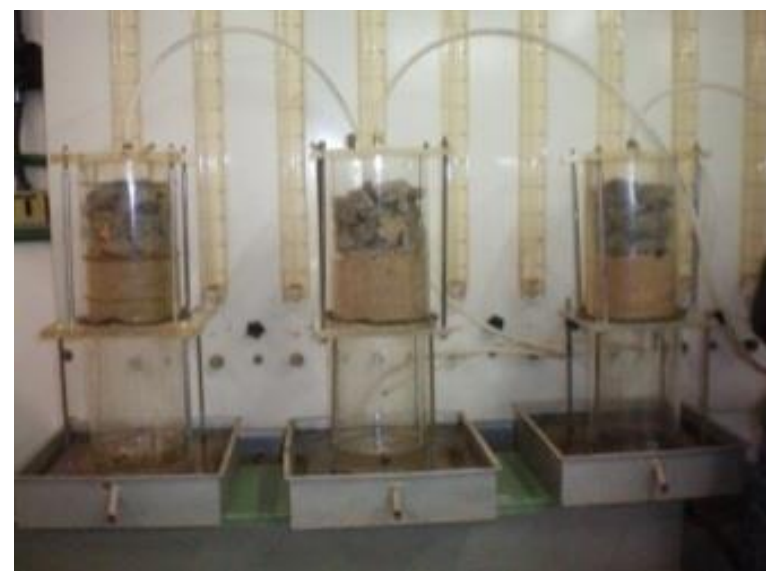

Filtro limpo

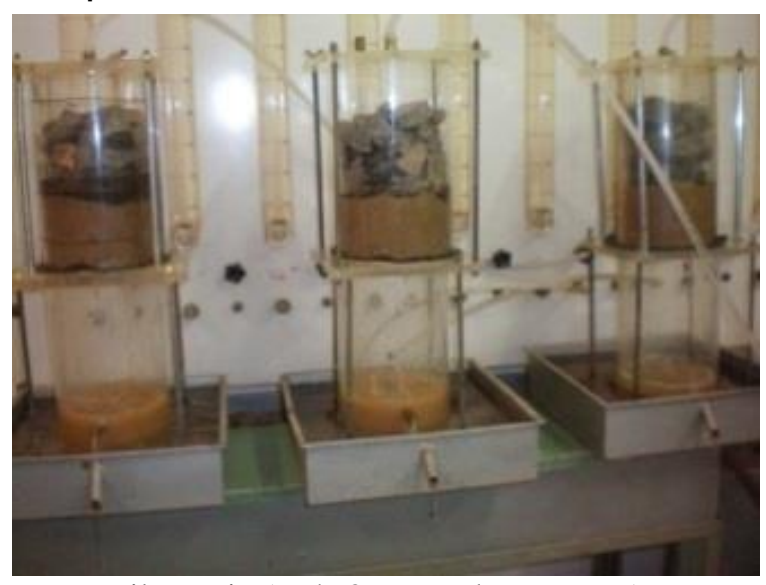

Filtro sujo (após 8 meses de operação)

Tabela 2 - Composições granulométricas do solo em diferentes profundidades nas proximidades do poço de infiltração

\begin{tabular}{c|c|c|c|c|c|c}
\hline \multirow{2}{*}{} & & \multicolumn{4}{|c}{ Composição granulométrica (\%) } \\
\cline { 2 - 6 } & \multirow{2}{*}{ Prof. (m) } & \multirow{2}{*}{ Argila } & \multirow{2}{*}{ Silte } & \multicolumn{3}{|c}{ Areia } \\
\cline { 5 - 7 } & & & Fina & Média & Grossa \\
\hline \multirow{3}{*}{ Poço de } & $0-0,40$ & $21 \%$ & $7 \%$ & $27 \%$ & $38 \%$ & $7 \%$ \\
infiltração & $0,60-0,80$ & $21 \%$ & $9 \%$ & $27 \%$ & $32 \%$ & $11 \%$ \\
& $1,0-1,2$ & $26 \%$ & $5 \%$ & $27 \%$ & $34 \%$ & $8 \%$ \\
& $1,4-1,6$ & $28 \%$ & $6 \%$ & $26 \%$ & $32 \%$ & $8 \%$ \\
& $1,8-2$ & $31 \%$ & $7 \%$ & $23 \%$ & $30 \%$ & $9 \%$ \\
\hline
\end{tabular}

Tabela 3 - Reduçãoda permeabilidade do geotêxtilem amostras de geotêxtil novas e amostras de geotêxtil após 8 meses de funcionamento

\begin{tabular}{|c|c|c|c|c|}
\hline & & \multicolumn{2}{|c|}{ Permeabilidade (mm/h) } & \multirow{2}{*}{$\begin{array}{c}\text { Variação }(\%) \\
\text { Geotêxtil com } 8 \\
\text { meses em relação } \\
\text { ao novo }\end{array}$} \\
\hline Amostra & Amostra* & $\begin{array}{l}\text { Geotêxtil } \\
\text { novo }\end{array}$ & $\begin{array}{l}\text { Geotêxtil com } 8 \text { mesesde } \\
\text { funcionamento }\end{array}$ & \\
\hline \multirow{4}{*}{ Tampa } & AMT1 & \multirow{4}{*}{$19.672,2$} & $17.436,8$ & $11,4 \%$ \\
\hline & AMT2 & & $14.660,6$ & $25,5 \%$ \\
\hline & AMT3 & & $15.085,8$ & $23,3 \%$ \\
\hline & AMT4 & & 14.502 .4 & $26,3 \%$ \\
\hline \multirow{6}{*}{ Paredes } & 1,0 a $1,5 \mathrm{~m}$ & \multirow{6}{*}{$19.672,2$} & $18.374,1$ & $6,6 \%$ \\
\hline & 0,50 a $1,0 \mathrm{~m}$ & & $19.941,4$ & $-1,4 \% * *$ \\
\hline & 0 a $0,50 \mathrm{~m}$ & & 18.754 .6 & $4,7 \%$ \\
\hline & 1,0 a $1,5 \mathrm{~m}$ & & $16.944,1$ & $13,9 \%$ \\
\hline & 0,50 a $1,0 \mathrm{~m}$ & & $19.758,4$ & $-0,4 \% * *$ \\
\hline & $0 * * *$ a $0,50 \mathrm{~m}$ & & $15.935,9$ & $19,0 \%$ \\
\hline \multirow{4}{*}{ Fundo } & AMF1 & \multirow{4}{*}{$19.672,2$} & $10.785,4$ & $45,2 \%$ \\
\hline & AMF2 & & $11.648,7$ & $40,8 \%$ \\
\hline & AMF3 & & $10.118,3$ & $48,6 \%$ \\
\hline & AMF4 & & $6.298,6$ & $68,0 \%$ \\
\hline
\end{tabular}

Nota: *amostras extraídas em posições distintas da tampa/filtro ou fundo em quadruplicatas, exceto na parede onde as amostras em duplicatas foram coletadas em alturas diferentes, contadas a partir do fundo do poço de infiltração.

**variação de $\pm 1 \%$ atribuída ao erro experimental.

***nível zero indica fundo. 
Outros trabalhos também avaliaram o efeito do geotêxtil em sistemas de infiltração. Lucas (2011) avaliouacolmatagem de geotêxtil e indicou que a redução média da permeabilidade do geotêxtil em todas as amostras de uma trincheira de infiltração por período de 1 ano foi de $45 \%$. As amostras foram coletadas a $0,3 \mathrm{~m}$, a $0,6 \mathrm{~m}$ e a $1,3 \mathrm{~m}$ em relação ao nível do solo em áreas circunzinhas e pertencentesà mesma microbacia hidrográfica do poço de infiltração investigado neste trabalho. Nesse trabalho, o poço de infiltração monitorado por 8 meses (data da realização do ensaio de permissividade do geotêxtil) apresentou redução média na manta geotêxtil de $51 \%$ nas amostras do fundo do poço, de $21 \%$ nas amostras da tampa, e de 7,7\% nas amostras da parede.

Tanto a trincheira apresentada por Lucas (2011) quanto este poçoforamexpostos ao carreamento de sólidos para o interior do sistema, devido à construção realizada em época chuvosa. Nopoço de infiltração monitorado por Reis, Oliveira e Sales (2008), por período de 10 meses, a redução da permeabilidade da manta geotêxtil do fundo foi de $32 \%$.

\section{Sobre os tempos de esvaziamento observados e calculados}

Foram simulados 11 eventos de chuva nos períodos de 22 de agosto de 2011 a 7 de janeiro de 2012. A profundidade útil máxima do poço foi de
$1,7 \mathrm{~m}$ (correspondendo a $1,5 \mathrm{~m}$ do poço e a $0,2 \mathrm{~m}$ do filtro e tampa), mas como houve rebaixamento do topo da tampa/filtro de $0,3 \mathrm{~m}$ em relação à superfície do solo, o nível máximo de água pode chegar a $2 \mathrm{~m}$ sem extravasamento da estrutura.

São apresentados na Tabela 4 todos os eventos de chuvasmonitorados: os totais (altura de chuva total medida, em $\mathrm{mm}$, e o volume medido, $\mathrm{em}^{3}$ ); as durações em horas e as intensidades médias das chuvas $(I$, medida em $\mathrm{mm} / \mathrm{h})$. O tempo de esvaziamento medido ( $D v$ medido) corresponde à diferença entre os instantes em que ocorreram o nível máximo no poço e a lâmina mínima de 20 $\mathrm{cm}$. Para o valor de $D v$ calculado, ver Equação 4, foi utilizado o volume máximo (Vmax), obtido indiretamente pelo emprego do método Puls, e a vazão de saída média (Qs), também obtida por meio do emprego do método de Puls, com o valor de Ko constante no tempo e otimizado, de modo a atender à condição de melhor ajuste entre os níveis de água medidos e modelados.

No decorrer da compilação dos dados obtidos em escala real e da modelagem matemática do tempo de esvaziamento, verifico-seque, para os níveis de água no interior do poço de infiltração inferiores a $20 \mathrm{~cm}$ em relação ao fundo,o tempo de esvaziamento calculado pelo método de Puls apresentou distanciamento dos valores observados.

Tabela 4 - Características dos eventos monitorados e tempos de esvaziamento

\begin{tabular}{|c|c|c|c|c|c|c|c|c|c|c|c|}
\hline 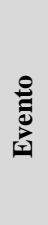 & 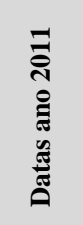 & 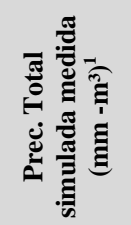 & 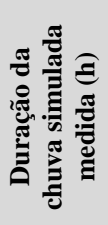 & 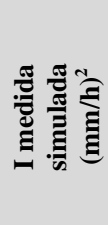 & & 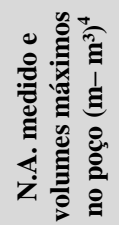 & 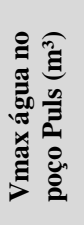 & 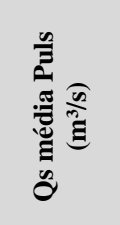 & 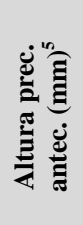 & 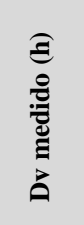 & 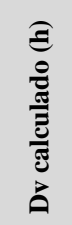 \\
\hline 1 & $22 / 08$ & $16,40-3,77$ & 0,68 & 23,43 & 2,0 & $1,33-2,52$ & 3,33 & $9,24 \times 10^{-5}$ & - & 10,05 & 10,17 \\
\hline 2 & $25 / 08$ & $18,30-4,20$ & 0,45 & 40,66 & 2,2 & $1,73-3,28$ & 4,02 & $6,13 \times 10^{-5}$ & - & 16,98 & 17,70 \\
\hline 3 & $01 / 09$ & $12,39-2,85$ & 0,53 & 23,23 & 2,0 & $1,24-2,35$ & 2,74 & $3,86 \times 10^{-5}$ & - & 17,45 & 19,45 \\
\hline 4 & $13 / 09$ & $8,99-2,07$ & 0,75 & 11,99 & 1,8 & $1,45-2,75$ & 2,04 & $2,27 \times 10^{-5}$ & - & 18,30 & 25,15 \\
\hline 5 & $20 / 10$ & $14,23-3,27$ & 0,47 & 30,49 & 2,1 & $1,26-2,37$ & 3,13 & $2,52 \times 10^{-5}$ & 0,00 & 32,22 & 30,00 \\
\hline 6 & $26 / 10$ & $16,97-3,90$ & 0,68 & 24,84 & 2,1 & $1,63-3,09$ & 3,72 & $2,66 \times 10^{-5}$ & 30,40 & 37,43 & 38,92 \\
\hline 7 & $08 / 11$ & $15,30-3,49$ & 0,75 & 20,40 & 2,0 & $1,42-2,69$ & 3,35 & $3,62 \times 10^{-5}$ & 0,51 & 24,77 & 25,74 \\
\hline 8 & $23 / 11$ & $12,23-2,81$ & 0,38 & 31,89 & 2,0 & $1,33-2,52$ & 2,66 & $1,71 \times 10^{-5}$ & 6,10 & 38,33 & 43,30 \\
\hline 9 & $28 / 11$ & $15,77-3,62$ & 0,73 & 21,51 & 2,0 & $1,88-3,56$ & 3,57 & $2,52 \times 10^{-5}$ & 7,37 & 37,42 & 39,98 \\
\hline 10 & $01 / 12$ & $16,79-4,39$ & 0,45 & 37,30 & 2,1 & $1,91-3,62$ & 4,39 & $2,88 \times 10^{-5}$ & 0,00 & 38,18 & 42,35 \\
\hline 11 & $07 / 12$ & $16,26-3,73$ & 0,52 & 31,47 & 2,1 & $1,82-3,45$ & 3,67 & $2,39 \times 10^{-5}$ & 1,79 & 40,22 & 42,65 \\
\hline
\end{tabular}

Nota: ${ }^{1}$ Prec.total medida = total de chuva simulada no poço em milímetros.

${ }^{2} \mathrm{I}(\mathrm{mm} / \mathrm{h})$ = razão entre o nível total descarregado e tempo de descarregamento.

${ }^{3}$ Calculado para a duração total do evento.

${ }^{4} \mathrm{~V}$ max. = volume máximo de água armazenado dentro do poço, em metros cúbicos.

${ }^{5}$ Altura prec. um dia antec. = altura de chuva total precipitada de um dia antecedente ao evento simulado em milímetros.

(-)Sem coleta de dados no pluviógrafo. 
Verificou-se que, a depender do nível de água dentro do poço de infiltração, a carga hidráulica assim como a colmatagem do fundo do poço, também influencianos valores dotempo de esvaziamento, pois a infiltração para níveis compreendidos entre a lâmina mínima de $20 \mathrm{~cm}$ e a lâmina máxima de água medida em cada ensaio (NAmax) éfortemente influenciada pela açãodas paredes do poço de infiltração, enquanto a contribuição da infiltração pelo fundo é relativamente pequena, devido a sua maior suscetibilidade ao depósito de material particulado fino. Já para lâminasde água inferiores a $20 \mathrm{~cm}$, o volume correspondente de água retido no interior do poçotem sua infiltração basicamente pelo fundo, em condição de carga hidráulica desfavorável.

Para ilustrar tal observação apresentam-se os resultados medidos nos tempos em que o volume correspondente a uma lâmina de $20 \mathrm{~cm}$ leva para se infiltrar no poço, e a porcentagem desses tempos em relação ao tempo total para esvaziamento medido no poço (Tabela 5).

Assim, tem-se que uma lâmina de água de $20 \mathrm{~cm}$, a qual resulta em um volume correspondente a $10 \%$ do volume total do poço, leva em média $32 \%$ do tempo total de esvaziamento do poço. Dessa forma, ao se considerar esse tempo no cômputo geral do esvaziamento, introduz-se um erro decorrente do distanciamento desse valor em relação ao valor médio observado, distorcendo o resultado final das simulações. Por isso, os autores recomendam que as lâminas próximas ao fundo sejam desconsideradas no cômputo do tempo de esvaziamento, quando da modelagem matemática do fenômeno.
Destaca-se ainda que o erro de medida do equipamento usado, como em qualquer outro, é mínimo para condições de fundo de escala, e viceversa. Assim, menores lâminas de água carregam maiores erros em suas medidas. Isso explica algumas imprecisões de medidas em pequenas lâminas de água, tal como ocorreu nos eventos 3, 4 e 11, em que foram identificados problemas nas medições com o sensor de nível para lâminas abaixo de $5 \mathrm{~cm}$ e $19 \mathrm{~cm}$. Nos eventos 3 e 4 o sensor mediu somente até a lâmina mínima de 5 $\mathrm{cm}$, e no evento 11 a lâmina mínima medida foi de $19 \mathrm{~cm}$. Tais fatos corroboram para a adoção de $20 \mathrm{~cm}$ como lâmina mínima a ser modelada.

Para os eventos 1, 2, 3, e 4 não houve precipitação antecedente nesse período. Já os outros eventos (6 ao 11) sofreram interferência das precipitações antecedentes.

É sabido que os tempos de esvaziamento do poço de infiltração dependem diretamente do coeficiente de permeabilidade do solo $(\mathrm{K})$, que neste trabalho foi admitido como constante no tempo. O valor $\mathrm{K}$, por sua vez, depende das condições de umidade antecedente do solo e pode assumir valores diferenciados no esvaziamento do poço a depender também da posição do nível de água no poço. Entretanto, a taxa de infiltração média koobtida indiretamente pelo método de Pulsobteve boa representatividade na determinação do tempo de esvaziamento para os onze eventos simulados. Observa-se na Figura 13 uma relação de 1:0,93, correspondente ao valor medido e calculado, com coeficiente de determinação da reta ajustada $\left(\mathrm{R}^{2}\right)$ de aproximadamente 0,96 .No gráfico, alinha tracejada representa a reta de ajuste perfeito $(1: 1)$. A linha contínua representa a reta ajustada por regressão linear.

Tabela 5 - Tempo de infiltração para uma lâmina de $20 \mathrm{~cm}$ no poço de infiltração e sua relação ao tempo total de esvaziamento para cada evento

\begin{tabular}{c|c|c}
\hline Evento & Total de horas & \%* \\
\hline Evento 1 & 4,21 & 32,1 \\
Evento 2 & 6,01 & 27,9 \\
Evento 3 & 4,93 & 22,0 \\
Evento 4 & 5,21 & 22,2 \\
Evento 5 & 14,90 & 34,3 \\
Evento 6 & 15,63 & 31,7 \\
Evento 7 & 11,33 & 33,3 \\
Evento 8 & 19,0 & 35,4 \\
Evento 9 & 15,86 & 31,9 \\
Evento 10 & 15,73 & 31,2 \\
Evento 11 & - & - \\
Média & & $30,2 * *$ \\
\hline
\end{tabular}

Nota: (-) não medido;

*Resultados obtidos pelo monitoramento do nível de água durante os eventos estudados.

**Desconsiderado o evento 11. 
Figura 13 - Relação entre os tempos de esvaziamento calculados e medidos do poço de infiltraçãocom erro médio de $9,6 \%$, em módulo

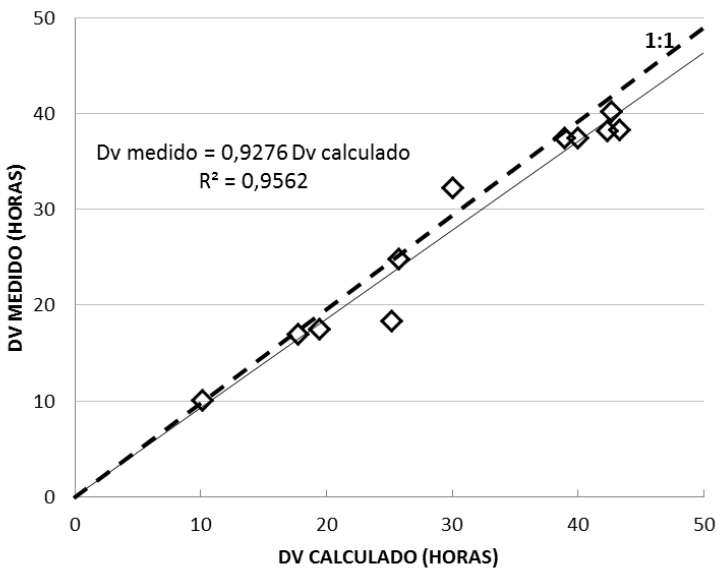

\section{Análise da permeabilidade do solo}

Somente para corroborar os dados apresentados neste artigo, menciona-se o trabalho apresentado por Carvalho (2008), em quesão apresentadosresultados de ensaios e verificado que a concepção do poço interfere na capacidade de infiltração dele. A autora realizou análise da variabilidade das taxas de infiltração da água no solo em poços com diferentes concepções e registrou que a taxa de infiltração média dos poços escavados a trado (poços piloto) é 63 vezes a taxa de infiltração média do poço revestido em tubos de concreto armado, pré-moldado e perfurado, e de 33 a 83 vezes a taxa de infiltração média de poços revestidoscom tijolo maciço e assentados em crivo.

Reis, Oliveira e Sales (2008) construírame monitoraram um poço de infiltração experimental no campus da Universidade Federal de Goiás (UFG) com dimensões de $1,10 \mathrm{~m}$ de diâmetro interno e $1,30 \mathrm{~m}$ de profundidade, sendo $0,30 \mathrm{~m}$ do fundo preenchido com britan ${ }^{\circ} 1$ envolta em manta geotêxtil, formando uma camada filtrante. Da mesma formaque no presente estudo, foram utilizados dois poços de monitoramento (tubos perfurados), envoltos com manta geotêxtil. Para tanto, os autores observaram uma situação contrária, pois verificaram que a capacidade de infiltração de água de chuva foi de 4 a 19 vezes maior que a de um poço sem revestimento e escavado a trado, com a mesma profundidade.

Neste estudo, observou-se que a permeabilidade média do poço escavado a trado (ensaios preliminares) de $10 \mathrm{~cm}$ de diâmetro e com a mesma profundidade do poço em escala real foi 2,6 vezes maior que a permeabilidade média calculada para o poço de infiltração (ko), sendo essas médias de $90,7 \mathrm{~mm} / \mathrm{h}$ para o poço menor e de $34,7 \mathrm{~mm} / \mathrm{h}$ para o poço construído em escala real.
Evidentemente, as particularidades de cada sistema, de suas experimentações e do meio físico influenciaram nos resultados obtidos.

\section{Conclusões}

Esse trabalho teve como objetivo o estudo de um poço de infiltração com a finalidade de controle de enchentes. Foi investigada a retenção de material pulverulento em um dispositivo tampa/filtro, bem como na manta geotêxtil instalada nas paredes e fundo do sistema de infiltração. O tempo de esvaziamento do poço também foi analisado e modelado matematicamente.

A análise do teor de material pulverulento na tampa/filtrodemonstrou a capacidade desse componente em reter finos. A média da retenção de materiais finos no filtro nos ensaios depois de 4 e 8 meses de funcionamento foi de $45 \%$.

Aumento de materiais finos na areia do filtro pôde ser constatado indiretamente pelos ensaios de permeabilidade do filtro da tampa. A permeabilidade dos filtros monitorados teve redução média de $19,4 \%$ em relação aos filtros limpos. A brita apresentou baixa capacidade de retenção de finos, sendo esse percentual de $0,13 \%$ nos ensaios amostrados 8 meses após a construção do poço.

Após 8 meses de funcionamento verificou-se redução da permeabilidade da manta geotêxtil do fundo, parede e tampa de 50,7\%, 7,7\% e 21,2\% respectivamente. Assim, fica evidente a eficácia das mantas geotêxteis colocadas no fundo e na tampa do poço, pois sem elas a capacidade de infiltração do solo poderia ser reduzida, comprometendo a vida útil do sistemade infiltração. Ensaios em longo termo devem ser realizados para avaliar a vida útil do sistema, todavia é patente a necessidade de manutenção

104 Barbassa, A. P.; Angelini Sobrinha, L.; Moruzzi, R. B. 
desses sistemas, de modo a garantir seu bom funcionamento.

A manta geotêxtil interna ao poço foi facilmente substituída e também reteve finos. Verificou-se que a entrada de finos no interior do poço foi proveniente do carreamento de sólidos para o poço devido à construção em período chuvoso. Todavia, a manta geotêxtil instalada minimizou o impacto sobre a capacidade de infiltração do sistema.

É importante mencionar que, mesmo considerando a redução da permeabilidade da manta geotêxtil, decorrente da retenção de material pulverulento em sua condição mais desfavorável, o valor médio de permeabilidade de $9.712 \mathrm{~mm} / \mathrm{h}\left(2,7 \times 10^{-3} \mathrm{~m} / \mathrm{s}\right)$ é muito superior à capacidade de infiltração do solo (da ordem de $5,5 \times 10^{-6} \mathrm{~m} / \mathrm{s}$ ), não sendo assim o geotêxtil limitante à infiltração de água.

No que tange à avaliação do tempo de esvaziamento, foram simuladas chuvas por meio do descarregamento de água de reservatório. Os eventos simulados obtiveram intensidade média de $27 \mathrm{~mm} / \mathrm{h}$, duração média de $35 \mathrm{~min}$ e tempo de retorno de 2 anos, de acordo com a equação de chuvas da cidade de São Carlos, SP.

Os tempos de esvaziamentos são parâmetros importantes de projeto e podem ser alterados durante a operação do sistema de infiltração, devido ao carreamento de material pulverulento para o interior das unidades. A correspondência entre o tempo de esvaziamento determinado para projeto e aquele obtido durante a operação do sistema de infiltração é fundamental para o bom funcionamento da unidade. Sistemas com baixa capacidade de infiltração terão elevados valores de tempo de esvaziamento, podendo, inclusive, ser acima do estipulado em projeto. Nesses casos, o poço de infiltração pode conter água remanescente de evento pretérito, diminuindo sua capacidade de atenuação de enchentes. Neste artigo, os valores calculados indiretamente pelas vazões médias simuladas por meio do método de Puls tiveram boa representatividade dos tempos medidos, apresentando relação de 1:0,93 (medido:calculado), com erro médio entre os tempos calculados e medidos de $9,6 \%$ e coeficiente de determinação $\left(\mathrm{R}^{2}\right)$ de 0,97 .

\section{Referências}

\section{AMERICAN SOCIETY FOR TESTING AND}

MATERIAL. D 4491-99a: standard test methods for water permeability of geotextiles by permittivity. West Conshohocken, 1999.
AMERICAN SOCIETY FOR TESTING AND MATERIAL. D 4716: standard test method for determining the (in-plane) Flow Rate per Unit Width and Hydraulic Transmissivity of a Geosynthetic Using a Constant Head. 2008.

ANGELINI SOBRINHA, L. Monitoramento e Modelagem de Um Poço de Infiltração de Águas Pluviais Construído em Escala Real. São Carlos, 2012. 149 f. Dissertação (Mestrado em Engenharia Urbana) - Escola de Engenharia, Universidade Federal de São Carlos, São Carlos, 2012.

ASSOCIAÇÃO BRASILEIRA DE NORMAS TÉCNICAS. NBR 13292: determinação do coeficiente de permeabilidade dos solos granulares à carga constante. Rio de Janeiro, 1995.

\section{ASSOCIAÇÃO BRASILEIRA DE NORMAS}

TÉCNICAS. NBR 7219: agregados: determinação do teor de materiais pulverizados. Rio de Janeiro, 1987.

\section{ASSOCIATION FRANÇAISE DE}

NORMALISATION. NF G 38017: porometrie: détermination de l'ouverture de filtration. SaintDenis, 1999.

BAPTISTA, M. B.; NASCIMENTO, N. O.; BARRAUD, S. Técnicas Compensatórias em Drenagem Urbana. Porto Alegre: ABRH, 2005.

BARBASSA, A. P. Simulação do Efeito da Urbanização Sobre a Drenagem Pluvial da Cidade de São Carlos, SP. São Carlos, 1991. 327 f. Tese (Doutorado em Hidráulica e Saneamento) Universidade de São Paulo, São Carlos, 1991.

BLIJENBERG, H.M. et al. Investigation of Infiltration Characteristic and Debris Flow Initiation Conditions in Debris Flow Source Areas Using a Rainfall Simulator. Hydrological Processes, v. 10, p. 1527-1543, 1996.

CARVALHO, E. T. L. Avaliação de Elementos de Infiltração de Águas Pluviais na Zona Norte da Cidade de Goiânia. Goiânia, 2008. 214 f. Dissertação (Mestrado em Geotecnia) - Faculdade de Geotecnia, Universidade Federal de Goiás, Goiânia, 2008.

CHAHAR, B. R.; GRAILLOT, D.; GAUR, S. Storm-Water Management Through Infiltration Trenches. Journal of Irrigation and Drainage Engineering, v. 138, n. 3, p. 274-281, 2012.

CHOPRA, M. B.; STUART, E.; WANIELISTA M. P. Pervious Pavement Systems in Florida: research results. In: INTERNATIONAL LOW IMPACT DEVELOPMENT CONFERENCE: REDEFINING WATER IN THE CITY, San Francisco, Califórnia, 2010. Proceedings... San Francisco, Califórnia, 2010. 
COUGHLIN, J. P.; CAMPBELL, C. D.; MAYS, D. C. Infiltration and Clogging by Sand and Clay in a Pervious Concrete Pavement System. Journal of Hydrology Engineering, v. 17, p. 68-73, 2012.

CUDWORTH JÚNIOR, A. G. A Water Resources Technical Publication. In: CUDWORTH JUNIOR, A. G. Flood Hydrology Manual. Denver: United States Government Printing Office.Denver, 1989.

CUNHA, A. P. S. R. Experimento Hidrológico Para Aproveitamento de Águas de Chuva usando Coberturas Verdes Leves (CVL). Universidade de São Paulo, São Carlos, 2004, 41 p. (Projeto de Pesquisa FAPESP: 03/06580-7).

FRENI, G.; MANNINA, G.; VIVIANI, G. Assessment of Data Availability Influence on Integrated Urbandrainage Modelling Uncertainty. Environment Modelling\& Software, v. 24, n. 10, p. 1171-1181, 2009.

GALAVOTI, R. C. Proposta de Um Modelo de Gestão Integrada de Águas Urbanas em Escala de Lote Residencial: alcances e limitações. São Carlos, 2012. 278 f. Tese (Doutorado em Hidráulica e Saneamento) - Universidade de São Paulo, São Carlos, 2012.

GEOFORT. Catálogo. Disponível em: <http://www.obergeo.com.br/imagens/esp_geofort _impressao.gif >. Acesso em: 2 maio 2014.

GÖBEL, P. et al. Recommended Urban Storm Water Infiltration Devices For Different Types of Run-Off Under Varying Hydrogeological Conditions. Journal of Soils and Sediments, Urban Impact on Soils and Groundwater, v. 8, n. 4, p. 231-238, 2009.

GOMEZ-ULLATE, E. et al. Analysis and Contrast of Different Pervious Pavements For Management of Storm-Water in a Parking Area in Northern Spain. Water Resources Management, v. 25, n. 6, p. 1525-1535, 2011.

KAWATOKO, I. E. S. Estabelecimento de Cenários de Medidas Estruturais e NãoEstruturais Para Gestão das Águas Urbanas em Escala de Lote. São Paulo, 2012. $130 \mathrm{f}$. Dissertação (Mestrado em Hidráulica e Saneamento) - Universidade de São Paulo, São Paulo, 2012.

LIMA, V. C. G. da R. Análise Experimental e Numérica de Trincheiras de Infiltração em Meio Não Saturado. São Calos, 2009. 168 f. Dissertação (Mestrado em Hidráulica e Saneamento)- Universidade de São Paulo, São Carlos, 2009.
LUCAS, H. A. Monitoramento e Modelagem de Um Sistema Filtro-Vala-Trincheira de Infiltração em Escala Real. São Carlos, 2011. 159 f. Dissertação (Mestrado em Engenharia Urbana) - Escola de Engenharia, Universidade Federal de São Carlos, São Carlos, 2011.

MARYLAND DEPARTMENT OF THE ENVIRONMENT. Construction Specifications For Infiltration Practices. In: MARYLAND DEPARTMENT OF THE ENVIRONMENT. 2000 Maryland Stormwater Design Manual. Baltimore: MDE, 2000.

OHNUMA JÚNIOR, A. A. Medidas Não Convencionais de Reservação d'Água e Controle da Poluição Hídrica em Lotes Domiciliares. São Carlos, 2008. 309 f. Tese (Doutorado em Hidráulica e Saneamento) Universidade de São Paulo, São Carlos, 2008.

PAIVA, J. B. D.; PAIVA, E. M. C. D. (Orgs.). Hidrologia Aplicada à Gestão de Pequenas Bacias Hidrográficas. Porto Alegre: ABRH, 2003.

PREFEITURA MUNICIPAL DE SÃO CARLOS. Dados da Cidade: geográfico e demográfico. Disponível em:

<http://www.saocarlos.sp.gov.br/index.php/conhec a-sao-carlos/115442-dados-da-cidade-geograficoe-demografico.html>. Acesso em: 19 abr. 2012.

REIS, R. P. A; OLIVEIRA, L. H.; SALES, M. M. Sistemas de Drenagem na Fonte Por Poços de Infiltração de Água Pluvial. Ambiente Construído, Porto Alegre, v. 8, n. 2, p. 99-117, abr./jun. 2008.

ROJAS-GUTIERREZ, L. A. Avaliação da Qualidade da Água de Chuva e de Um Sitemafitro-Vala-Trincheira de Infiltração no Tratamento do Escoamento Superficial Direto Predial em Escala Real em São Carlos - SP. São Carlos, 2011. Dissertação (Mestrado em Engenharia Urbana) - Programa de Pós-Graduação em Engenharia Urbana, Universidade Federal de São Carlos, São Carlos, 2011.

SCHUELER, T. R. Controlling Urban Runoff: a practical manual for planning and designing urban BMPs. Washington, DC: Department of Environmental Programs, 1987.

SILVA, B. L. et al. Avaliação da Infiltração em Revestimentos Com Superfícies Permeáveis. Revista Ingenieríadel Agua, v. 16, n. 3, p. 1-10, 2009.

SOUZA PINTO, C. de. Curso Básico de Mecânica dos Solos em 16 Aulas. São Paulo: Oficina de Textos, 2000. 
STANCATI, G.; NOGUEIRA, J. B.; VILAR, O. M. Ensaios de Laboratório em Mecânica dos Solos. São Carlos: Universidade de São Paulo, 1981.

TAVANTI, D. R.; BARBASSA, A. P. Análise dos Desenvolvimentos Urbanos de Baixo Impacto e Convencional. Revista Brasileira de Recursos Hídricos, v. 17, p. 1-10, 2012.

URBONAS, B.; STAHRE, P. Stormwater: best management practices and detention. Englewood Cliffs, NJ: Prentice Hall, 1993.
ZOLFAGHARI, A. A.; MIRZAEE, S.; GORJI, M. Comparison of Different Models For Estimating Cumulative Infiltration. International Journal of Soil Science, v. 7, n. 3, p. 108-115, 2012.

\section{Agradecimentos}

Esta pesquisa foi desenvolvida no âmbito do Projeto MCT/Finep/CT - Hidro Processos Hidráulicos 02-2007, intitulado Quantidade, Qualidade, Tratamento e Aproveitamento de Águas Pluviais (GPF 1375) e do MAPLU (2009).

\section{Ademir Paceli Barbassa}

Departamento de Engenharia Civil, Centro de Ciências Exatas e de Tecnologia | Universidade Federal de São Carlos | Rodovia Washinton Luiz, Km 235 | São Carlos - SP - Brasil | CEP 13560-970 | Tel.: (16) 274-8262 Ramal 240 | E-mail: barbassa@ufscar.br

\section{Loide Angelini Sobrinha}

Departamento de Hidráulica e Saneamento, Escola de Engenharia de São Carlos | Universidade de São Paulo | Av. Trabalhador Sãocarlense, 400, Cidade Jardim | São Carlos - SP - Brasil | CEP 13566-590 | Tel.: (16) 274-8262 | E-mail: loideangelini@gmail.com

\section{Rodrigo Braga Moruzzi}

Departamento de Planejamento Regional, Instituto de Geociências e Ciências Exatas de Rio Claro | Universidade Estadual Paulista Júlio de Mesquita Filho | Avenida 24 A, 1515, Bela Vista | Rio Claro - SP - Brasil | CEP 13506-900 | Tel.: (19) 3526-9339 |

E-mail: rmoruzzi@rc.unesp.br

\section{Revista Ambiente Construído}

Associação Nacional de Tecnologia do Ambiente Construído

Av. Osvaldo Aranha, $99-3^{\circ}$ andar, Centro

Porto Alegre - RS - Brasil

CEP $90035-190$

Telefone: +55 (51) 3308-4084

Fax: +55 (51) 3308-4054

www.seer.ufrgs.br/ambienteconstruido

E-mail: ambienteconstruido@ufrgs.br 